\title{
Her2neu Amplification Associates with Co-deletion 1p/14q in Recurrent Meningiomas
}

\author{
Brenda O. Hamilton, Joanne S. Sy, Joseph F. Megyesi, Lee Cyn Ang
}

\begin{abstract}
Background: The current methods to predict recurrence and aggressive behaviour of meningiomas rely mainly on histological grading, histological subtype, proliferative index, as well as brain invasion. In many instances, histological grade alone fails to predict recurrence in the grade I and grade II meningiomas. Deletions of $1 \mathrm{p}$ and $14 \mathrm{q}$ have previously been reported to correlate with poor prognosis in terms of either recurrence or higher histological grades. The Her2neu (ErbB2) amplification has been shown to be a useful predictor of aggressive behaviour in breast and ovarian tumours, but its significance in meningioma is so far uncertain. Method: In order to determine the cytogenetic differences between 22 recurrent and 25 non-recurrent meningiomas of all grades, we used fluorescent in situ hybridization (FISH) DNA probes for 1p36,14q11.2 and 17q11.2-12 (Her2neu) on formalin fixed paraffin embedded (FFPE) tissue from the Brain Tumour Tissue Bank (BTTB), London Health Science Center (LHSC). Results: We showed a positive association for meningioma recurrence correlated with 1 p36 deletion plus or minus 14q 11.2 deletions in all grades of meningiomas. The Her2neu amplification was strongly associated with $1 \mathrm{p} / 14 \mathrm{q}$ co-deletion in cases of recurrent meningiomas, especially the higher grade tumours. Conclusion: These cytogenetic markers can be applied in addition to histological grading for predicting the risk of recurrence and biological behaviour.
\end{abstract}

RÉSUMÉ: Amplification de Her2neu 1p/14q dans les méningiomes récurrents. Contexte : Les méthodes actuelles pour prédire une récidive et un comportement agressif des méningiomes sont fondées principalement sur le grade histologique de la tumeur, son sous-type histologique, l'indice de prolifération et l'envahissement de la tumeur. Dans plusieurs cas, le grade histologique seul ne prédit pas la récidive dans les méningiomes de grade I et de grade II. Des délétions $1 \mathrm{p}$ et $14 \mathrm{q}$ ont été rapportées antérieurement comme étant corrélées à un mauvais pronostic en ce qui concerne la récidive ou à un grade histologique supérieur. Il a été démontré que l'amplification de Her2neu (ErbB2) est un facteur de prédiction utile d'un comportement tumoral agressif dans les tumeurs du sein et de l'ovaire, mais sa signification dans le méningiome demeure incertaine. Méthode : Nous avons utilisé l'hybridisation in situ avec sonde fluorescente d'ADN (FISH) des régions 1p36, 14q11,2 et 17q11,2-12 (Her2neu) sur du tissu inclus dans la paraffine provenant de la Brain Tumour Tissue Bank (BTTB) du London Health Science Center. Résultats : Nous avons démontré qu'il existe une association positive entre la récidive du méningiome et une délétion 1p36 plus ou moins 14q11,2 quelque soit le grade du méningiome. L'amplification de Her2neu était fortement associée à une co-délétion $1 \mathrm{p} / 14 \mathrm{q}$ dans les cas de méningiomes récurrents, spécialement pour les tumeurs de plus hauts grades. Conclusion : Ces marqueurs cytogénétiques peuvent êtres utilisés comme complément de la classification de la tumeur pour prédire le risque de récidive et le comportement biologique de la tumeur.

Can J Neurol Sci. 2013; 40: 361-365

Meningiomas are classified into three grades according to the World Health Organization (WHO) with grade I representing about $80 \%$, grade II 15 to $20 \%$ and grade III $1-2 \%$ of the tumours. ${ }^{1}$ The histological grading aims to predict recurrence and biological aggressiveness, with the higher grades exhibiting higher recurrence rates and poorer outcomes. However in spite of gross total resection, benign histopathology and lack of brain invasion there is still recurrence in $7-25 \%$ of grade I meningiomas. ${ }^{2}$ Therefore, factors other than the histology, degree of resection, age of patient or location of tumour may influence meningioma recurrence. Loss of heterozygosity (LOH) or inactivation of the NF2 gene on $22 \mathrm{q}$ is known to initiate the tumourigenesis of grade I meningiomas but deletions of $1 \mathrm{p}$ and/or $14 \mathrm{q}$ appear to be associated with tumour progression to higher grades. The losses of chromosomes $22 \mathrm{q}$, $1 \mathrm{p}$ and $14 \mathrm{q}$ found in an aggressive subset of low grade meningiomas have been suggested as predictors of recurrence. ${ }^{3}$
As well, a small group of relapsed patients with benign recurrent tumours exhibited deletions of chromosomes $1 p$ and $14 q .{ }^{4}$ Low grade benign large tumours with monosomy 14 and deletion 1 p36 have indicated a high risk of early relapse after surgery and deletion $14 \mathrm{q}$ analysis has been suggested as a test for recurrence in benign meningiomas. ${ }^{5,6}$ Gains of chromosome $1 \mathrm{q}$ and amplification of $17 \mathrm{q}$ have been correlated with a shorter progression free survival in atypical meningiomas and anaplastic

From the Department of Molecular Pathology (BOH), Department of Clinical Neurosciences (JFM), Department of Neuropathology (LCA), London Health Science Center, London, Ontario, Canada; Department of Neuropathology (JSS), University of Sydney, NSW 2006, Australia.

Received October 23, 2012. Final Revisions Submitted November 23, 2012 Correspondence to: Brenda Hamilton, Molecular Pathology, London Health Science Center, Victoria Hospital, 800 Commissioners Rd E, London, Ontario, N6A 5W9, Canada. Email: brenda.hamilton@1hsc.on.ca. 
tumours. ${ }^{7,8}$ The Her2neu oncogene at $17 q 11.2-q 12$ is noted to be amplified in $\sim 30 \%$ of breast and ovarian cancers, correlating with a poor patient prognosis. ${ }^{9}$ The prognostic role of Her2neu amplification in meningiomas remains controversial. To determine the association of Her2neu amplification with $1 \mathrm{p}$ and $14 \mathrm{q}$ deletion, and the roles these molecular events play in recurrence, we studied two groups of meningiomas: one recurrent and the other non-recurrent to determine the difference in $1 \mathrm{p}, 14 \mathrm{q}$ and Her2neu status between the two groups.
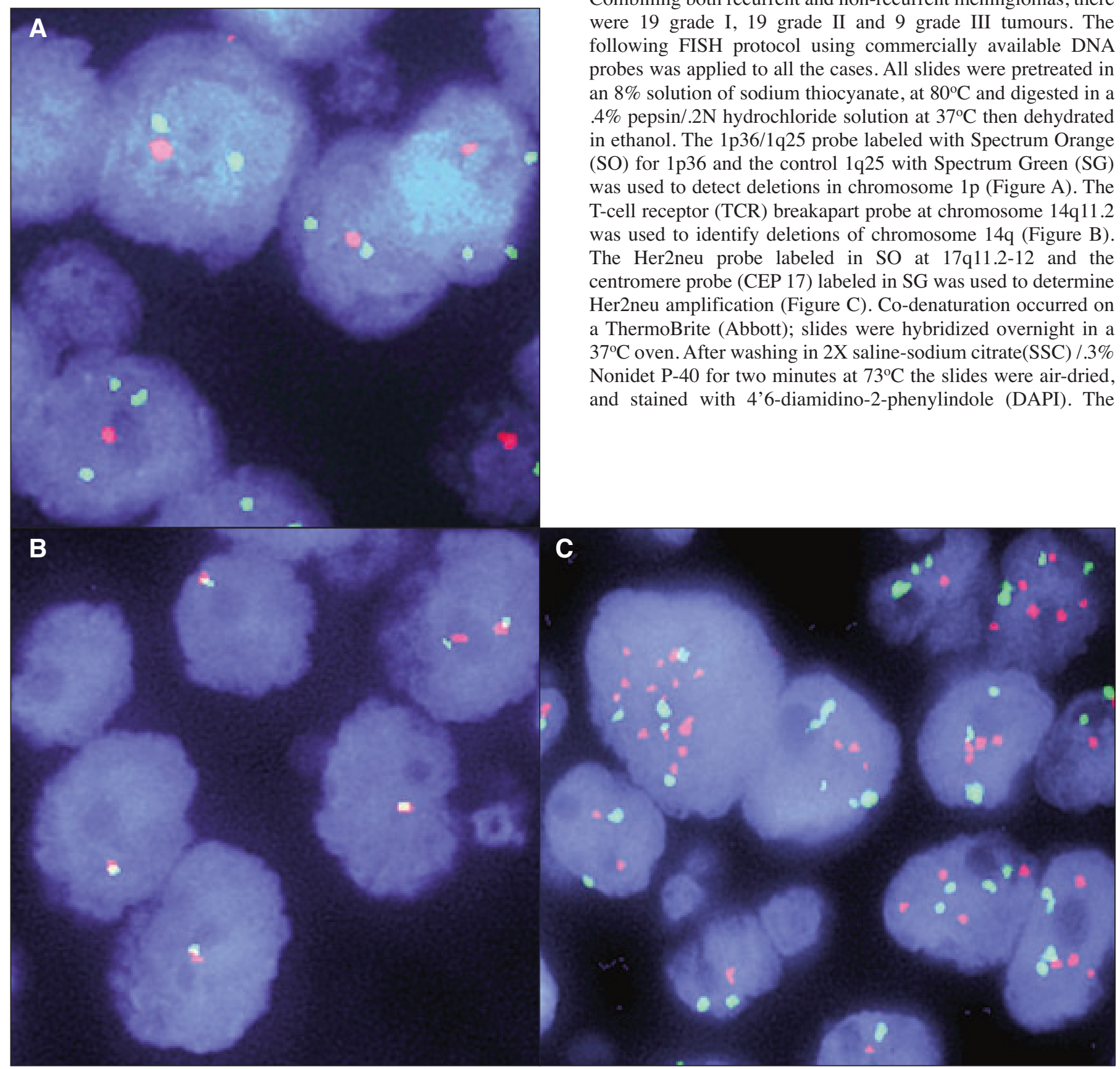

Figure: Grade II Recurrent meningioma case. A. Deletion 1p36 65\%. B. Deletion 14q11.2 42\%. C. Her2neu amplification Ratio 2.1:1.

\section{Materials AND Methods}

Formalin fixed paraffin embedded meningioma tissue samples were selected from the BTTB at LHSC, London, Ontario. After reviewing the histological diagnoses and grades, 22 recurrent and 25 non-recurrent cases were selected (total =47). The non-recurrent meningiomas were selected from a group of patients who had been followed up from 5 to 15 years without known recurrence. For the recurrent meningiomas, the mean time interval between initial resection and recurrence was 4.9 years. Of the 22 recurrent tumours, 8 were grade I, 8 were grade II and 6 were grade III; of the 25 non-recurrent tumours, 11 were grade I, 11 were grade II, and 3 were grade III. Combining both recurrent and non-recurrent meningiomas, there were 19 grade I, 19 grade II and 9 grade III tumours. The following FISH protocol using commercially available DNA probes was applied to all the cases. All slides were pretreated in an $8 \%$ solution of sodium thiocyanate, at $80^{\circ} \mathrm{C}$ and digested in a $.4 \%$ pepsin $/ .2 \mathrm{~N}$ hydrochloride solution at $37^{\circ} \mathrm{C}$ then dehydrated in ethanol. The 1p36/1q25 probe labeled with Spectrum Orange (SO) for $1 \mathrm{p} 36$ and the control 1q25 with Spectrum Green (SG) was used to detect deletions in chromosome 1p (Figure A). The T-cell receptor (TCR) breakapart probe at chromosome 14q11.2 was used to identify deletions of chromosome 14q (Figure B). The Her2neu probe labeled in SO at 17q11.2-12 and the centromere probe (CEP 17) labeled in SG was used to determine Her2neu amplification (Figure C). Co-denaturation occurred on a ThermoBrite (Abbott); slides were hybridized overnight in a $37^{\circ} \mathrm{C}$ oven. After washing in $2 \mathrm{X}$ saline-sodium citrate(SSC) $/ .3 \%$ Nonidet P-40 for two minutes at $73^{\circ} \mathrm{C}$ the slides were air-dried, and stained with $4^{\prime} 6$-diamidino-2-phenylindole (DAPI). The 
Table 1: Summary of results for all recurrent and nonrecurrent cases combined

\begin{tabular}{l|l|l}
\hline & Recurrent & Non-recurrent \\
\hline Total n=47 cases & $\mathbf{2 2}$ & $\mathbf{2 5}$ \\
\hline $1 \mathrm{p} 36$ deletion & $20 / 22(91 \%)$ & $4 / 25(16 \%)$ \\
\hline $14 q 11.2$ deletion & $15 / 22(68 \%)$ & $3 / 25(12 \%)$ \\
\hline Co-deletion $1 \mathrm{p} / 14 \mathrm{q}$ & $15 / 22(68 \%)$ & $1 / 25(4 \%)$ \\
\hline Her2neu amp & $8 / 22(36 \%)$ & $2 / 25(8 \%)$ \\
\hline $\begin{array}{l}\text { Co-deletion } 1 \mathrm{p} / 14 \mathrm{q} / \\
\text { Her2neu amp }\end{array}$ & $8 / 22(36 \%)$ & $0 / 25(0 \%)$ \\
\hline
\end{tabular}

slides were viewed and captured under a Zeiss AxioImager M1 fluorescent microscope, equipped with the appropriate DAPI, Texas Red, and fluorescein isothiocyanate (FITC) triple, dual, and single filters sets. Two hundred cells were analyzed for deletions of $1 \mathrm{p} 36$, and $14 \mathrm{q} 11.2$ in all recurrent and non-recurrent meningiomas. The cut-off for deletion $1 \mathrm{p} 36$ and $14 \mathrm{q} 11.2$ was $25 \%$ (previously established on non-neoplastic tissue). Sixty cells were analyzed for amplification of Her2neu gene on each case. An overall ratio of $>2: 1$ (SO to $\mathrm{SG}$ ) was considered amplified for the Her2neu gene. ${ }^{10,11}$ Statistical analysis was performed by the Department of Epidemiology and Biostatistics, Western University. Recurrent and non-recurrent meningiomas were compared using Chi-square analysis and Fisher's exact test for each DNA probe, on each single grade, and on combined grades I and II, II and III, and all grades I-III. A probability (P) value $<.05$ was considered significant.

\section{RESULTS}

Successful results were attained for each of the DNA probes, in all 47 meningiomas (22 recurrent and 25 non-recurrent). When all the recurrent meningiomas combined were compared to all the non-recurrent meningiomas, 1p36 deletion $(\mathrm{p}<.0001)$, $14 \mathrm{q} 11.2$ deletion $(\mathrm{p}<.0001), 1 \mathrm{p} / 14 \mathrm{q}$ co-deletion $(\mathrm{p}<.0001)$, Her2neu amplification $(\mathrm{p}=.03)$ and $1 \mathrm{p} / 14 \mathrm{q}$ co-deletion plus Her2neu amplification $(\mathrm{p}=.001)$ were significantly associated with the recurrent tumours (Table 1). All the recurrent meningiomas with Her2neu amplification also had 1p/14q codeletion, whereas amongst the non-recurrent tumours $1 \mathrm{p} / 14 \mathrm{q}$ codeletion was found only in one tumour but there was no association with Her2neu amplification. In the grade I tumours, deletion $1 \mathrm{p} 36(\mathrm{p}=.001)$, deletion $14 \mathrm{q} 11.2(\mathrm{p}=.018)$ and codeletion $1 \mathrm{p} / 14 \mathrm{q} \quad(\mathrm{p}=.018)$ were also significant in recurrent tumours (Table 2). The Her2neu amplification was detected in one recurrent grade I tumour but in none of the non-recurrent tumours. In the grade II tumours, deletion 1p36 ( $\mathrm{p}=.003)$, codeletion $1 \mathrm{p} / 14 \mathrm{q}(\mathrm{p}=.04)$ and the combination of $1 \mathrm{p} / 14 \mathrm{q} /$ Her2neu amplification ( $\mathrm{p}=.018)$ were significant for recurrence (Table 2). Combining grades I and II $(n=38)$ gave the following $\mathrm{p}$ values: for $1 \mathrm{p} 36(\mathrm{p}<.0001), 14 \mathrm{q} 11.2(\mathrm{p}=.005), 1 \mathrm{p} / 14 \mathrm{q}$ co-deletion $(\mathrm{p}=.0005)$ and $1 \mathrm{p} / 14 \mathrm{q} / \mathrm{co}$-deletion/Her2neu amplification $(p=.009)$ in the recurrent tumours. The sample size $(n=9)$ for the

Table 2: Results for deletion 1p36, deletion 14q11.2, codeletion $1 \mathrm{p} / \mathbf{1 4 q}$ and amplification of Her2neu for Grade I, II and III meningioma tumours.

\begin{tabular}{|c|c|c|}
\hline & 22 Recurrent & 25 Non-recurrent \\
\hline Grade I (19) & 8 & 11 \\
\hline 1p36 deletion & $6 / 8(75 \%)$ & $0 / 11(0 \%)$ \\
\hline $14 \mathrm{q} 11.2$ deletion & $4 / 8(50 \%)$ & $0 / 11(0 \%)$ \\
\hline Co-deletion $1 \mathrm{p} / 14 \mathrm{q}$ & $4 / 8(50 \%)$ & $0 / 11(0 \%)$ \\
\hline Her2 amp & $1 / 8(13 \%)$ & $0 / 11(0 \%)$ \\
\hline $\begin{array}{l}\text { Co-deletion } 1 \mathrm{p} / 14 \mathrm{q} / \\
\text { Her2 amp }\end{array}$ & $1 / 8(13 \%)$ & $0 / 11(0 \%)$ \\
\hline Grade II (19) & 8 & 11 \\
\hline 1p36 deletion & $8 / 8(100 \%)$ & $3 / 11(27 \%)$ \\
\hline $14 q 11.2$ deletion & $5 / 8(63 \%)$ & $3 / 11(27 \%)$ \\
\hline Co-deletion $1 \mathrm{p} / 14 \mathrm{q}$ & $5 / 8(63 \%)$ & $1 / 11(9 \%)$ \\
\hline Her2 amp & $4 / 8(50 \%)$ & $2 / 11(18 \%)$ \\
\hline $\begin{array}{l}\text { Co-deletion } 1 \mathrm{p} / 14 \mathrm{q} / \\
\text { Her2 amp }\end{array}$ & $4 / 8(50 \%)$ & $0 / 11(0 \%)$ \\
\hline Grade III (9) & 6 & 3 \\
\hline 1p36 deletion & $6 / 6(100 \%)$ & $1 / 3(33 \%)$ \\
\hline $14 q 11.2$ deletion & $6 / 6(100 \%)$ & $0 / 3(0 \%)$ \\
\hline Co-deletion $1 \mathrm{p} / 14 \mathrm{q}$ & $6 / 6(100 \%)$ & $0 / 3(0 \%)$ \\
\hline Her2 amp & $3 / 6(50 \%)$ & $0 / 3(0 \%)$ \\
\hline $\begin{array}{l}\text { Co-deletion 1p/14q/ } \\
\text { Her2 amp }\end{array}$ & $3 / 6(50 \%)$ & $0 / 3(0 \%)$ \\
\hline
\end{tabular}


grade III meningiomas was small and analysis results were not reliable, however a combination of grades II and III gave a larger sample size $(\mathrm{n}=28)$ and showed $1 \mathrm{p} 36$ deletion $(\mathrm{p}<.0001)$, $14 \mathrm{q} 11.2$ deletion $(\mathrm{p}=.003)$, co-deletion $1 \mathrm{p} / 14 \mathrm{q}(\mathrm{p}=.0001)$ and $1 \mathrm{p} / 14 \mathrm{q}$ co-deletion/Her2neu amplification $(\mathrm{p}=.006)$ were all significant in the recurrent tumours. Statistically, the positive predictive value for a meningioma of any grade with $1 \mathrm{p} 36$ deletion, 14q11.2 deletion or Her2neu amplification as being a recurrent tumour was significant $83 \%$ (95\% CI .63-.95) for $1 \mathrm{p} 36$, $83 \%(95 \%$ CI .59-.96) for $14 q 11.2$ and $80 \%$ (95\%CI .44-.97) for Her2neu amplification. Higher positive predictive value for a meningioma recurrence was noted with co-deletion of $1 p / 14 q$ at $94 \%$ (95\% CI .70-.99) and $1 \mathrm{p} / 14 \mathrm{q}$ co-deletion plus Her2neu amplification at $100 \%$ (95\% CI .63-1.00).

\section{DisCUSSION}

The results from this study indicated that loss of $1 \mathrm{p}$ with or without loss of $14 q$ could be an independent marker for recurrence, regardless of the histological grade. The frequency of $1 \mathrm{p} 36$ deletion increased with tumour grade. The 14q11.2 deletion always coincided with the $1 \mathrm{p} 36$ deletion, whereas the $1 \mathrm{p} 36$ deletion could occur singularly. The Her2neu amplification always co-existed with $1 \mathrm{p} / 14 \mathrm{q}$ co-deletions in recurrent tumours especially in the grade II and III tumours. Using FISH analysis on recurrent meningiomas, Cai et al, found the frequency of chromosome $1 \mathrm{p}$ deletion increased with the tumour grades; $23 \%$ of benign, $56 \%$ of atypical and $75 \%$ of anaplastic tumours. ${ }^{5}$ Pfisterer et al, noted deletion 1p in $35 \%$ of grade I, $69 \%$ of grade II and $100 \%$ of grade III tumours, but did not distinguish between recurrent and non-recurrent tumours. ${ }^{12}$ In comparison, we found deletion $1 p$ in $75 \%$ of grade I and $100 \%$ of both grade II and III recurrent meningiomas, whereas in the non-recurrent menigiomas, $1 \mathrm{p}$ deletion was noted in $0 \%$ of grade I, $27 \%$ of grade II, and $33 \%$ of grade III tumours. Grade I tumours without $1 \mathrm{p}$ deletions are not likely to recur. In our study there have been no recurrences for at least seven years. In contrast, the mean time for benign recurrent tumours with deletion $1 \mathrm{p} 36$ to relapse was 3.5 years. We suggest grade I recurrent meningiomas most likely contain underlying chromosome $1 \mathrm{p}$ abnormalities. Deletion $14 \mathrm{q}$ was found in $50 \%$ of benign tumours, $63 \%$ atypical tumours, and $100 \%$ in anaplastic tumours. The frequency of $14 \mathrm{q}$ deletion also increased with higher grades, and is always associated with recurrence. The behaviour of atypical meningiomas is difficult to predict and since atypical meningiomas have higher five year recurrence rates and carry increased morbidity and mortality rates than benign tumours, better biomarkers are needed to distinguish between the two. ${ }^{2}$ The presence of $1 p / 14 q$ codeletion can help to distinguish between benign and atypical meningiomas which will recur from those which will not recur. The addition of Her2neu amplification will further help to identify more aggressive recurrent tumours. We found Her2neu amplification was more frequent in the higher grades of recurrent cases. Only two cases of Her2neu amplification were found in the non-recurrent cases (8\%). All of our Her2neu amplified recurrent cases $(36 \%)$ were associated with $1 \mathrm{p} / 14 \mathrm{q}$ co-deletion (Table 1). The positive association of recurrent meningiomas with $1 \mathrm{p} / 14 \mathrm{q}$ co-deletion and Her2neu amplification was $100 \%$ for both grades II and III tumours. Our study suggests that 1p36 deletion is an early molecular event in tumourigenesis while $14 \mathrm{q}$ deletion and Her2neu amplification occur in more advanced stages of meningioma progression.

The Her2neu (ErbB2) oncogene is amplified in approximately $30 \%$ of breast and ovarian cancers, and this amplification is correlated with a poor prognosis for the patients. ${ }^{9}$ Several studies have used immunohistochemistry (IHC) for detection of Her2neu amplification in meningiomas with variable results, but there are rarer studies using DNA FISH probes. Previous IHC studies showed Her2neu protein (gp185) expression in non-neoplastic arachnoid cells and low grade meningiomas, without any overexpression in atypical and anaplastic meningiomas. ${ }^{13-15}$ Loussouarn et al, however, did not find any IHC staining of Her2neu in normal arachnoid cells, thus Her2neu was considered overexpressed if staining was visible in meningiomas. ${ }^{10}$ The IHC staining criteria for meningiomas differs from breast cancers, as $2+$ is assigned if $>50 \%$ and $<$ $90 \%$ of the cells showed membrane staining, and $3+$ if $>90 \%$ of the cells showed staining. Loussouarn et al, demonstrated both moderate (2+) and strong (3+) staining in their typical, and atypical/anaplastic tumours (ten cases). Fluorescent in situ hybridization was performed on the IHC positive cases, and four out of their ten cases showed Her2neu amplification. Amplification is defined as a Her2/CEP17 ratio $>2$. Half of their Her2 positive cases recurred and two of those recurrent cases were grade I meningiomas. The authors conclude that, although their sample size was small, Her2neu gene amplification may be an independent prognostic predictor of recurrence. ${ }^{10}$ Another study by Ozer et al, used FISH probes to detect Her2neu gene copy number on meningiomas and found the Her2neu gene was amplified (ratio > 2) in 13\% (7 out of 55) of their patients in all tumours regardless of the grades. ${ }^{11}$ The authors did not note any recurrence in the Her2 positive cases; however, the majority of their tumours were grade I with less likelihood of recurrence. They also were unable to make any conclusions about the significance of Her2neu amplification on disease progress, because of the small number of tumours with amplification. Recently, Abdelzaher et al, using IHC on benign tumours found a correlation between overexpression of Her2neu proteins with high proliferative indices and recurrence. ${ }^{16}$ Using both IHC and FISH Wang et al, showed Her2neu gene amplification coincided with increased tumour grades and recurrence. ${ }^{17}$ Laurendeau et al, using real-time reverse transcription polymerase chain reaction (RT-PCR) have demonstrated that Her2 (ErbB2) formed heterodimers with Her1 (ErbB1) in meningiomas, and suggested these heterodimers are associated with tumour survival and progression. ${ }^{18}$ Our FISH study has shown $50 \%$ of Her2neu amplified cases are strongly associated with co-deletion of $1 \mathrm{p} / 14 \mathrm{q}$ in higher grade recurrent meningiomas $(\mathrm{p}=.006$ for grades II/III). Although the putative genes on $1 p$ and $14 q$ are unknown, the Her2neu receptors are ideal targets for cancer therapy. ${ }^{18,19}$ Lapatinib, a small molecule tyrosine kinase inhibitor that targets Her2neu receptors has been approved by the American Food and Drug Administration (FDA) approved for the treatment of metastatic breast cancers, and is currently being evaluated for vestibular schwannoma. ${ }^{20}$ Testing for Her2neu amplification, along with deletions $1 \mathrm{p}$ and $14 \mathrm{q}$ could be a useful avenue to explore for the treatment of high grade recurrent meningiomas. 


\section{Conclusion}

In summary, this study demonstrated deletions of chromosome $1 \mathrm{p} 36$, alone, or in combination with deletion 14q11.2, are important independent predictors of meningioma recurrence. Deletion 1p36 is the most common deletion found in recurrent meningiomas, especially in benign tumours. Codeletion $1 \mathrm{p} / 14 \mathrm{q}$ has a strong association with recurrent tumours, and the combination of three cytogenetic abnormalities $1 \mathrm{p} / 14 \mathrm{q}$ co-deletion with Her2neu amplification is very strongly associated with aggressive recurrent meningiomas. Fluorescent in situ hybridization analysis for chromosome $1 \mathrm{p}$ and $14 \mathrm{q}$ deletions and Her2neu amplification, involving the use of simple and inexpensive techniques, can be reliable predictors for recurrence and aggressive behaviour in meningiomas.

\section{ACKNOWLEDGEMENTS}

The authors thank the Brain Tumour Tissue Bank, London Health Science Center and Dr. Subrata Chakrabarti, Chair, Department of Pathology, London Health Science Center.

\section{REFERENCES}

1. Perry A, Gutmann DH, Reifenberger G. Molecular pathogenesis of meningiomas. J Neurooncol. 2004;70:183-202.

2. Perry A, Louis DN, Scheithauver BW, Budka H, von Deimling A. Meningeal tumours. In: WHO Classification of tumours of the central nervous system. Louis DN, Ohgaki H, Wiestler OD, Cavenee WK, editors. 4th ed. Lyon, France: IARC Press, 2007. p. $163-72$.

3. Pfisterer WK, Hendricks WP, Scheck AC, et al. Fluorescent in situ hybridization and ex vivo $1 \mathrm{H}$ magnetic resonance spectroscopic examinations of meningioma tumor tissue: is it possible to identify a clinically-aggressive subset of benign meningiomas? Neurosurgery. 2007;61:1048-61.

4. Al-Mefty O, Kadri PAS, Pravdenkova S, Sawyer JR, Stangeby C, Husain M. Malignant progression in meningioma: documentation of a series and analysis of cytogenetic findings. J Neurosurg. 2004;101:210-18.

5. Cai DX, Banerjee R, Scheithauer BW, Lohse CM, KleinschmidtDeMasters BK, Perry A. Chromosome $1 \mathrm{p}$ and $14 \mathrm{q}$ FISH analysis in clinicopathologic subsets of meningioma: diagnostic and prognostic implication. J Neuropathol Exp Neurol. 2001;60: 628-36.

6. Maillo A, Orfao A, Espinosa AB, et al. Early recurrences in histologically benign/grade 1 meningiomas are associated with large tumors and coexistence of monosomy 14 and del (1p36) in the ancestral tumor cell clone. Neuro Oncol. 2007;9:438-46.
7. Buschges R, Ichimura K, Weber RG, Reifenberger G, Collins VP. Allelic gain and amplification on the long arm of chromosome 17 in anaplastic meningiomas. Brain Pathol. 2002;12:145-53.

8. Jansen M, Mohapatra G, Betensky RA, Keohane C, Louis DN. Gain of chromosome arm 1q in atypical meningioma correlates with shorter progression-free survival. Neuropathol Appl Neurobiol. 2012;38:213-19.

9. Slamon DJ, Clark GM, Wong SG. Human breast cancer: correlation of relapse and survival with amplification of the Her-2/neu oncogene. Science. 1987; 235:177-82.

10. Loussouarn D, Brunon J, Avet-Loiseau H, Campone M, Mosnier JF. Prognostic value of Her2 expression in meningiomas: an immunohistochemical and fluorescence in situ hybridization study. Hum Pathol. 2006;37:415-21.

11. Ozer O, Sahin FI, Aydemir F, Ozen O, Yilmaz Z, Altinors N. Her2/neu gene amplification in paraffin-embedded tissue sections of meningioma patients. Turk Neurosurg. 2009;19: $135-8$.

12. Pfisterer WK, Hank NC, Preul MC, et al. Diagnostic and prognostic significance of genetic regional heterogeneity in meningiomas. Neuro Oncol. 2004;6:290-9.

13. Andersson U, Guo D, Malmer B, et al. Epidermal growth factor receptor family (EGFR, ErbB2-4) in gliomas and meningiomas. Acta Neuropathol. 2004;108:135-42.

14. Chozick BS, Benzil DL, Stopa EG, et al. Immunohistochemical evaluation of erbB-2 and p53 protein expression in benign and atypical human meningiomas. J Neurooncol. 1996;27:117-26.

15. Schlegel J, Ulrich B, Stumm G, et al. Expression of the c-erbB-2encoded oncoprotein and progesterone receptor in human meningiomas. Acta Neuropathol. 1993;86:473-9.

16. Abdelzaher E, El-Gendi SM, Yehya A, Gowil AG. Recurrence of benign meningiomas: predictive value of proliferative index, BCL2, p53, hormonal receptors and HER2 expression. Br J Neurosurg. 2011;25:707-13.

17. Wang CL, Mei JH, Wang SS, Xu S, Xu LL, Xiong YF. Expression of HER2/neu in meningiomas: an immunohistochemistry and fluorescence in situ hybridization study. [Zhonghua Bing Li Xue Za Zhi] Chin J Pathol. 2010;39:156-60.

18. Laurendeau I, Ferrer M, Garrido D, et al. Gene expression profiling of ErbB receptors and ligands in human meningiomas. Cancer Invest. 2009;27:691-8.

19. Gradishar WJ. Her 2 therapy -an abundance of riches. N Engl J Med. 2012;366:176-8.

20. Ammoun S, Cunliffe $\mathrm{CH}$, Allen JC, et al. ErbB/HER receptor activation and preclinical efficacy of lapatinib in vestibular schwannoma. Neuro Oncol. 2010;12:834-43. 